\title{
Spatial, Temporal and Structural Usages of Pashto Case Marker 'Ta'
}

\author{
Raj Wali Khan ${ }^{1}$, Muhammad Iqbal ${ }^{1} \&$ Muhammad Anwar ${ }^{2}$ \\ ${ }^{1}$ Department of English, Islamia College University, Peshawar, Pakistan \\ ${ }^{2}$ Department of English, Federal Urdu University of Arts, Science and Technology, Islamabad, Pakistan \\ Correspondence: Raj Wali Khan, PhD Scholar, Department of English, Islamia College University, Peshawar, \\ Pakistan. E-mail: rwalikhan@gmail.com
}

Received: December 18, 2019 Accepted: February 5, 2020 Online Published: March 1, 2020

doi:10.5539/ijel.v10n2p383 URL: https://doi.org/10.5539/ijel.v10n2p383

\begin{abstract}
Pashto is an Indo-Iranian language which expresses different semantic aspects and functions with the help of case markers. The post-position \& case marker $\boldsymbol{T} \boldsymbol{a}$ has the quality to posit many types of usages i.e. temporal, spatial and structural in Pashto language. In the research on Pashto syntax, Khan (2009), Roberts (2000) and Tegey and Robson (1996) have described the phenomenon of case marker ' $\mathbf{T a}$ ' but have not been investigated extensively. This study follows Ahmed (2006) to analyze in detail different functions and usages of $\boldsymbol{T a}$ in terms of semantic and syntactic principles and provides a unified account for these diverse usages and their meanings. The analyses confirm that $\boldsymbol{T a}$ as a case marker is not only used for Dative case as a subject but it has a polysemous nature in terms of spatial and non-spatial (structural, temporal) usages. The non-spatial usages are the extension of its spatial origin in the semantic field that is metaphorically spatial by default. Besides temporal and structural $\boldsymbol{T} \boldsymbol{a}$ usages can be extended to purpose, reason, obligations, immediate future, perception, ability and inability in relations to DAT (as a SUBJ or OBJ) in Pashto language.
\end{abstract}

Keywords: Spatial, Temporal, Structural, Pashto Dative case marker, Ta, Post-position

\section{Introduction}

Pashto as an Indo-Iranian language is mostly spoken by 25 million speakers as a national and first language in the south, southwest and east Afghanistan, regional language in the north west of Pakistan called Khyber-Pakhtunkhwa and most of the central Asia, Europe and America by the migrants as their first language (Hamid \& Bukhari, 2017; O’Leary, Rensch, \& Hallberg, 1992; Penzl, 1961; Roberts, 2000; Skalmowski, 1996). Pashto is written in Arabic script (Aslamzai \& Saad, 2015; Zuhra \& Khan, 2009). Many studies (Khan, 2009; Penzl, 1954, 1961; Tegey \& Robson, 1996) have been conducted to study Pashto language in different perspectives. One area of increasing attention, is to study ad-positions (pre-position, post-position and ambi-position) in Pashto language in detail. This paper focuses on the only one post-position "Ta" with different spatial, temporal and structural usages in Pashto language.

Table 1. Case markers in South Asian languages

\begin{tabular}{lll}
\hline Cases & Pashto & Urdu \\
\hline Nominative & $\boldsymbol{\emptyset}$ & $\emptyset$ \\
Ergative & $\boldsymbol{\varnothing}$ & $\mathrm{Ne}$ \\
Accusative & $\boldsymbol{\emptyset}$ & $\mathrm{Ko}$ \\
Dative & $\mid \mathrm{ta} \backslash-$ or $\backslash \mathrm{la} \backslash$ & $\mathrm{Ko}$ \\
Instrumental & $\mathrm{Sara} / \mathrm{puh}+\mathrm{N}+$ bandi & $\mathrm{Se}$ \\
Genitive & $\mathrm{Da} / \mathrm{sara} / \mathrm{na}$ & $\mathrm{Ki}$ \\
Locative & $\mathrm{Pe} / \mathrm{pe} . . \mathrm{ke} / \mathrm{de} \ldots$ para etc & $\mathrm{Me} / \mathrm{par} / \mathrm{tak}$ \\
\hline
\end{tabular}

The paper is organized as follows, Section (2) provides relevant literature, section (3) describes method and material. Section (4) outlines different usages of "Ta" as a case marker at SUBJ and OBJ positions, section (5) deals with its analyses and their meaning, while section (6) provides conclusion, section (7) consists of acknowledgement and section (8) provides relevant references. 


\section{Literature Review}

Khan (2009, pp. 55-56) has investigated Pashto prepositions and post positions in terms of spatial usages. According to Khan (2009) ' $t a$ ' and ' $l a$ ' as case markers can be used allative and benefactive in Pashto language. As his study focuses on spatial expressions in South Asian language, so, he has not paid full attention to study ' $t a$ ' as a case marker in detail. Tegey and Robson (1996, p. 154) have discussed Pashto grammar in which they have tried to describe most of the grammatical aspects of Pashto language but they have not examined this case marker in minutiae.

Similarly, Khattak (1988) has studied Pashto verbs with inflections that pinpoint tense, case, voice, mood and aspect. He further adds that position of subjects and objects of verbs also require inflections for person, number and genders. According to Khattak (1988) morphologically, Pashto has only two tenses: past and present but he has rarely identified and discussed the role of case maker ' $t a$ ' extensively. Penzl (1954) and Babrakzai (1999) also support that agreement in Pashto language is based on inflections that records a nominal's inherent features usually person and numbers. Likewise, David (2013) has also provided certain details about preposition and post-positions in Pashto but has not rigorously investigated the phenomenon of post-position ' $t a$ ' in detail. MacKenzie (2003) has also described Pashto language traditionally. He has mentioned that in Pashto, case relationships are expressed by pre and post position or combination of both but failed to provide a clear picture of post-positioned " $\mathrm{Ta}$ " in his work on Pashto. Masood and Rahman (2013) are the other researchers who have provided data on structural case assignment in Pashto according to Minimalist perspective. Masood (2014) and Masood and Rahman (2015, p. 105) have concluded that " $\phi$-features agreement between the functional head T and a nominal results in assigning nominative Case to that nominal while $\phi$-features agreement between the functional head small $v$ or Voice (depending on tense) and a nominal results in assigning accusative Case to that nominal". The study of Masood (2014) and Masood and Rahman (2015) were not able to discuss this phenomenon of case marker "Ta" semantically and syntactically in a unified manner. Similarly, Rahman and Bukhari (2014) have worked on Pashto case system and provided a good review on Pashto case allocation. They were unable to describe this case marker solely in their study.

The previous studies have not directly addressed ' $t a$ ' case marker in Pashto language in detail that is why this study aims to investigate this polysemous phenomenon in a unified way.

\section{Method and Material}

The researchers have used descriptive method to explain and analyze Pashto language structures. The material used in this study is based on Pashto grammar books, written in Pashto, Urdu and English languages. The researchers have selected the past research (traditional or modern) as a source for the selection of sentences for the purpose of analysis. After selection of sentences, they were checked by two native speakers for grammaticality and semantic acceptability. Furthermore, the researcher is also a native speakers of Pashto language and has spent his life in Pashto language community. Therefore, he has utilized his own knowledge of Pashto language in this research.

\section{Uses of Case Marker ' $T a$ '}
1) $\mathrm{Ma}$
bilal-ta (Note 2) chegha
owahalla.
(Dative Object)
I. Sg. NOM bilal. Sg-DAT cry
do (PRS-PRF)
I cried to Bilal.
2) Ali Imad-ta milavida-la laro.
Ali.Sg.NOM. imad.SG.NOM meet go (PST)
(Dative Object)
(Purpose)

Ali went to meet imad.

3) Hagha-Ta aram wargy.

(Dative Subject)

$\mathrm{He}=\mathrm{SG}-\mathrm{DAT}$

rest

came (PST)

(Experiencer)

He is relieved.

4) Maa ahmad-ta kitab workro,

I=SG.M ahmad=SG,M-DAT book give (PST)

(Dative Object,)

I give a book to ahmad.

5) Ahmad-ta kitab

milao shoo.

(Recipient/Goal)

Ahmnad=SG.M-DAT book recieve be (PST)

(Dative Subject)

(Recipient/Goal) 
Ahmad receive the book.

6) Ahmad-ta cancer dey.

Ahmad=M.Sg-DAT cancer have/suffer (PRT IMP)

(Dative Subject)

(Experiencer)

Ahmad is suffering from cancer.

7) Ali jumath-ta laro.

(Spatial Adverb)

Ali=Sg. M mosque-DAT go (PST)

Ali went to mosque.

8) Ahmad makham-ta raghaly wo

Ahmad evening- DAT. Come (PST)

(Temporal)

(Point in time)

Ahmad came at evening.

9) Cha-ta obe pekar de.

Who.Pl-DAT. water need be) (PRST)

Who do need water?

10) Ali ahmad-ta jerra rawostha.
Ali.Sg.NOM
ahmad.SG.DAT weep
make (PRS.PRF)
(Causee)

(Dative Object)

Ali makes ahmad to weep.

11) Ali karachi-ta laro.

Ali.SG.NOM. karachi.To. All. go PRST.PRF

(Dative object)

(Goal)

Ali went to krachi

\section{Analysis of Usages of $\mathbf{T a}$}

The previous section has provided multiple usages of "ta" as a case marker in Pashto language. Most of these usages are different but related in terms of its locative and recipient roles as primary in nature, other allocations are based on semantic extension with temporal and eventual properties of ' $\boldsymbol{t} \boldsymbol{a}$ '.

\subsection{Spatial Usages}

' $\boldsymbol{T a}$ ' as a case marker is used as locative adjunct to pinpoint the semantic movement of an agent 'towards the point or goal' or 'at end point of an action'.

12) Ahmad

kor ta

orasedo.

Ahmsad.M. Sg .

Home SG

DAT reach. Pst.Perf

Ahmad has reached to home.

13) Shahid

Islamabad-ta

laro.

Shahid.M.Sg.NOM.

Islamabad.M.Sg-DAT

go.Pst-Perf

Shahid has gone to Islamabad.

14) Moter showroom-ta

ra-worasedo.

Car.M.Sg. showroom.M.Sg-DAT

arrive. Pst.

The car arrived at home.

In (12)-(14) ta is used in the sense of end point. Other usages of this case marker can be extension in terms of the spatial meanings of ta.

\subsection{Temporal Aspect of ' $t a$ '}

The case marker ' $\boldsymbol{t a}$ ' is also used for ' $a$ point in time' just like ' $k o$ ' in Urdu language (Ahmed, 2006). It can be referred to specify a part of time or portion of time at day, night, months and years. These temporal usages are shown in (15)-(17).
15) Ali
ba
makham-ta
razi.

$\begin{array}{llll}\text { Ali.M.Sg. fut. Evening.N.Sg-DAT come. Fut. } & \text { cot }\end{array}$

Ali will come at evening. 


$\begin{array}{lccccc}\text { 16) } \text { Hagh } & \text { ba } & \text { jummy-ta } & \text { duai } & & \text { raweri. } \\ \text { He.M.Sg } & \text { fut } & \text { Friday.N.Sg-DAT } & \text { medicine.N.SG } & & \text { bring. Fut. } \\ \text { He will bring medicine on Friday. } & \text { saba-ta } & \text { pukhtona } & \text { okra } & \\ \text { 17) Tha } & \text { tomorrow.F.SG-DAT } & \text { ask } & & \text { be Fut. } \\ \text { You.M.Sg } & & & & \\ \text { You ask tomorrow. } & & & \end{array}$

In all the above usages (15)-(17), the semantic features of 'ta' are 'point in temporal semantic field' instead of an end point in spatial field. These above temporal aspects can be represented with another post-position "la" (18) and (19) can provide a clarity to this replacement.
18) Hagha
ba jummy-la
He.M.Sg
Fut FridayN.SG-DAT
duai
medicine.N.Sg
raweri.
He will bring medicine on Friday.
19) Thə
saba-la
You.M.Sg.
tomorrow.N.Sg-DAT
pukhtona
okera. ask be.Fut.

You ask tomorrow.

\subsection{Causal Domain of 'ta' and Its Extension to Other Semantic Aspects}

Use of ' $\boldsymbol{t a}$ ' inside the argument structure of a verb allow this case marker to extend end point semantics to the causal domain. It is used as a recipient that receive something either physical or abstract.

\subsection{Dative Object}

" $\mathbf{T a}$ " marks the indirect object of the ditransitive verbs where the object plays the role of the recipient as a participant in the argument structure of the clause in Pashto language. (19) and (20) explore this semantic aspect of second argument in the clauses.
20) Asad
ahmad-ta
kitab
workero.

Asad.M.Sg. ahmad.M.Sg-DAT book.N.Sg give.Pst.

Asad gave book to ahmad.

21) Ali

asad-ta

khat

wolekelo.
Ali.M.Sg.
asad.M.Sg-DAT
letter Sg.
Write. Pst.

Ali wrote a letter to asad.

In (20) the book is received by Ahmad who is the indirect object in the sentence. While in (21) Asad is the recipient of the letter who is also the goal of the letter. In (20) and (21) 'ta' confirms the role of the recipient and goal respectively. According to Ahmed (2006, p. 6) and Grimm (2005), 'recipients are sentients who undertake a quality change, relative to the state of affairs before at the onset of an event i.e., a direct action'. Ahmad (2009) further explains that 'recipient is a location which is the goal or destination of the object'.

Besides the recipient role of indirect object, dative subjects in Pashto also adhere to the role of recipient in terms of both physical and abstract levels. In (22) and (23) the dative subjects confirm the role of recipient.

22) Ahmad-ta

Ahmad.M.SG-DAT

Ahmad got/received the book.

\section{kitab}

book.N.Sg.

milao sho.

$$
\text { receive/get.PST. }
$$

$\begin{array}{lll}\text { saza } & \text { warkery } & \text { shwa. } \\ \text { punishment } & \text { give } & \text { be.Pst }\end{array}$

Asad received the punishment.

In (22) and (23) the verbs malao (get/receive) and warkery (give) in Pashto language require a sentient recipient. According to Butt, Grimm, and Ahmed (2006) and Mohanan (1994, pp. 141-150) the sentient recipients are used as dative subjects because they fulfill the requirements of subject-hood of sentient as human argument in the clause. Verma and Mohanan (1990) support that dative subjects are found cross-linguistically and are a standard part of South Asian languages in terms of receiver role. 


\subsection{Psyche Verbs and Dative Subjects}

In above (20)-(23) the dative subjects performed the role of a recipient but this phenomenon can be extended to human mental domain in terms of psyche verbs. These verbs show the dative subjects (the sentient agents) as an experiencer of an action in the structure. These sorts of constructions involve semantic properties of experiencer (mental state) and unintentional actions by the subjects.

\subsubsection{Experiencer}

One of the well-known qualities of psyche verbs are generally the shifting of recipient role into an experiencer in dative constructions because the object that was receiving something (goal) is now allocated to the subject and is psychologically affected by some event of the action. Examples (24)-(26) are explain this concept.

$\begin{array}{lll}\text { 24) Ahmad-ta } & \text { cancer } & \text { dey. } \\ \text { Ahmad-DAT } & \text { cancer } & \text { be (PST-IMF) }\end{array}$

Ahmad suffers from cancer.

25) Asad-ta aqal raghy.

Asad-DAT wisdom come (PST-PRF)

Asad has become wise.

26) Ali-ta

khabera

oraseda.

Ali-DAT

matte/problem

reached/listened. (PST)

Ali listened the matter/Lit: Ali listened about the problem.

According to Landau (2005, p. 9) and Ahmed (2006) experiencers are mental location and psyche predicates project human minds as the location of these experiences and are considered as GOALS. There are two types of experiencer i.e., Self-experiencer and Caused experiencer.

\subsubsection{Self-Experiencer}

According to Khattak (1988, p. 146) the self-experiencer undergoes an experience on his own with reference to some objects. No other agent is required to enforced the subject to experience the action as in $(27 \& 28)$ respectively .

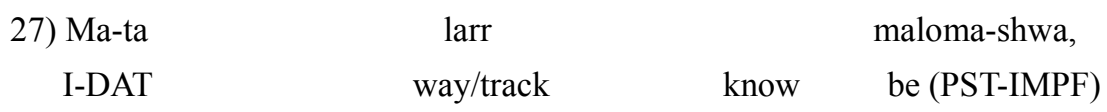

I got the way. (Lit: I get the knowledge of journey)

28) Badsha-ta xapla wada

The king-DAT

his promise

rwyada

shwa.

The king has remembered his own promise.

\subsubsection{Caused-Experiencer}

In this regard the experiencer needs a causee to let him experience something. This experience may be enforced or volitional in terms of the subject as an experiencer. (29) and (30) provide clarification of this phenomenon.
29) Ma-ta
ahmad
larr
okhidulo.
I -DAT
Ahamd (causee)
track
show/lead (PST-PRF)

Ahamd had shown me the way/ahmad had lead me to the way.

$\begin{array}{rccccc}\text { 30) Badsha-ta } & \text { ma } & \text { xpela } & \text { wadha } & \text { reyada kara. } & \\ \text { King-DAT } & \text { I (cause) } & \text { his } & \text { promise } & \text { rememeberd. } & \text { (Khattak, 1988) }\end{array}$

I remembered/reminded the king his promise.

The above examples (29) and (30) indicate that the Dative subjects could have the role of self-experiencer or they can be caused by another causee to experience certain abstract concepts as in (28) and (29). Saksena (1980) calls the causee-expereincer as the affected agents. According to Saksena (1980) and Ahmed (2006), affected agents are subjects of intransitive and ingestive verbs.

31) Asad-ta loga olageda.

Asad-DAT Hunger feel (PST) 
Asad felt hungery/the hunger.

$\begin{array}{lrrr}\text { 32) Asad-ta } & \text { de-salan-boea-na } & \text { loga } & \text { olegeda. } \\ \text { Asad-DAT } & \text { loc } \quad \text { dish aroma=loc } & \text { hunger } & \text { feel. (PST) }\end{array}$

Asad felt hunger due to the scent of the dish.

The subjects in (30) and (31) are affected by the action/state (hunger) and they are considered as the recipient of the action. The affected agents are marked with "ta" case marker in (28)-(31). All these subjects are caused by someone or something in the action. According to Ahmed (2006), the syntax of these causative structure is similar to ditransitive verbs as an indirect object. In the above examples (30) and (31) " $t a$ " refers to the receiving of the hunger of subject (Asad).

\subsection{Extension of " $t a$ " to Event Argument}

\subsubsection{Purpose/Reason}

Like Urdu "ko" (Ahmed, 2006; Rizvi, Butt, \& King, 2008), in Pashto language the Dative case marker "ta" is used with clausal adjunct to express the purpose and reason of the action. Examples (33) and (34) explore the same phenomenon of purpose and reason.
33) Halakan
lobe/sair-ta
laral.
Boys
match/walk-DAT
go (PST)

Boys went for the match/walk.

34) Pallar

wadhe/dua=la/ta (Note 3)

laro.

Father

marriage/ pray-DAT

go (PST)

Father went for a marriage/pray (on death of someone).

The usages of " $t a$ " in (33-34) are similar in nature with spatial usages, though it is abstract and metaphorically referring to travelling towards an event instead of location which is specific end point event having a specific purpose.

\subsubsection{Immediate Future}

Most interesting fact of " $t a$ " is to refer to the immediate future of the action that will be accomplished by the subject. In this way "ta" elucidates the beginning of an event in near future. (35) and (36) refer to the action of the subject Maryam that will be completed in immediate future.
35) Maryam
de korr jarroo kolo-ta
zea
Maryam
(gen) home sweeping-DAT
go (pres)
Maryam is going to sweep/clean the home.
36) Maryam
rotie pakkholo-la/ta
zea.
Maryam
bread making-DAT
go (pres)

Maryam is going to make the dough/bread

According to Ahmad (2006), this immediate future usage is based on the semantics feature of end point. The subject in these constructions is very near to the event at abstract level. Semantically, "ta" has the meaning of very near, or almost there, so it refers to the immediate future.

\subsubsection{Obligation}

The Dative case marker "ta" usages can be extended to the constructions that manifest certain types of obligation and needs. These constructions require modal auxiliary "pekar-de" to be used at the end of the sentence with a Dative Subject Construction.

$\begin{array}{rrrrr}\text { 37) Aslam-ta } & \text { de-mesharano } & \text { adab } & \text { kwal } & \text { pekar-dey. } \\ \text { Aslam-DAT } & \text { gen elders } & \text { respect } & \text { do } & \text { want (perc) }\end{array}$

Aslam needs to respect theelders.

$\begin{array}{lllll}\text { 38) } \begin{array}{l}\text { Ahmad-ta } \\ \text { Ahmad-DAT }\end{array} \text { his } & \text { karr } & \text { kawl } & \text { pekar-dey. } \\ \text { Ahmad needs to do his } & \text { work. } & \text { do } & \text { want (perc) }\end{array}$


39) Insan-ta

pe har karr-ke

soch

kawl pekar-dey.

Human-DAT

gen every work-in

think

do

want (perc)

Human need to think in every work.

Just like 'cahiye' in Urdu (Ahmed, 2006), pekar-dey (needs/want to), in Pashto, is a percative form of verb. pekar which means 'want' and these verbs are bound to use in imperative constructions with nominative subjects whereas, in Pashto it is used with Dative subjects that refers to the needs or obligation on behalf of the subject as in sentences (37)-(39).

This pekar-dey (needs/want to) factor above can also be seen in terms of different requirements having necessity on event for the subject.

40) Mashom-ta loga

lagedally da

Child -DAT hunger

feel

be (PRS)

The child is hungry/the child feels hunger.

41) Ma-ta de-sehath yabi

dua

okerae.

I -DAT (gen) healthy

pray

do (pres)

I need prayer for my health.

In (40) and (41) the requirement of food (for hunger) and pray (for health) is necessary for the subject respectively. So, we can say that DAT case marker "ta" can be used for necessity as well.

5.6.4 Perceptions, Liking and Disliking

The case marker "ta" can be extended in its usages to the perception, liking and disliking of the subjects towards an object.

42) Ma-ta jerra/khenda

razzi

I-DAT weep/smile come (pres)

I feel like weeping/smiling.

43) hagha-ta

$$
\begin{gathered}
\text { da gady khe lagi. } \\
\text { Dem-car good be (pres) }
\end{gathered}
$$

He-DAT

He likes this car.

44) Ahmad-ta torr rang maza ne warkawi.

Ahmad-DAT black color like neg feel.

Ahmad does not like black color.

In example (42) the subject perceives to weep or smile while in (43) and (44) the dative subjects like the car and dislike the black color respectively. So, these sentences also confirm that "ta" can be used for perception, liking and disliking as well.

5.6.5 Ability and Potentiality

"Ta" as a case marker can be used with subjects to show the ability, inability and potentialities of the subject in doing or performing some acts.

45) Ma-ta/la khaberi razi.

I-DAT talk know'PRS.

I have the ability to talk./I can talk.

46) Haghe-la/ta topak chalol warzi.

He-DAT gun use be.PRS

I can use the gun/I can use a gun

47) Tha-ta

You-DAT de.

be. PRS

You remember the answers. 
48) Haghe-ta English ne-warzi.

He-DAT English neg-know. PRS

He does not know English/ he is unable to speak English.

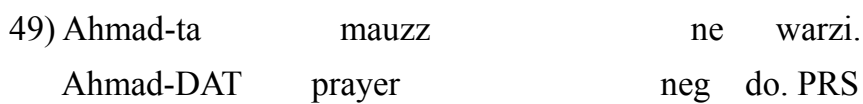

Ahmad cannot offer the prayer/Ahmad does not know the prayer.

Example (45) and (46) assume the ability of the subject that he has the skill to talk or use the gun, similarly (47) confirms the ability of the subject to know the answers of all the question while in (48) and (49) both the subjects are incapable to speak/know English and prayer respectively which shows the inability of the doer. All these subjects are DAT-SUBJ in nature so we can say that "ta' case marker can be extended to these semantic aspects as well.

\subsubsection{Possession and Relation}

" $\mathrm{Ta}$ " as a case marker for dative case is sometimes used to express relation or possession of person instead of genitive case.

50) Haga thukhfa tche wa plarr ma-ta rawastelli. (Saiful-ul-Muluk cited in raverty: 196)

That curiosity/gift which father-me-DAT sent (PST)

That curiosity/gift which the father had sent for me

\section{Conclusion}

This study has examined diverse usages of Pashto language dative case marker and post-position "ta" and confirms that this post-position is not restricted to the core locative spatial use only but it can be extended to other non-spatial usages like spatial, temporal, eventual, obligation, perception, ability, inability, liking, disliking and perceptions as well. These non-spatial usages are metaphorically spatial by default in nature. Furthermore, DAT SUBJ usage is also stretched to the mental states where the sentient agent receives an experience and these experiences are metal locations. The research also approves that all these diverse non-spatial usages are based on end point results in space and time.

\section{Acknowledgments}

I am thankful to Faisal Faran and Shahid Khan for their help in terms of grammaticality and semantic acceptability of various sentences used in this article. Without their help, it would be difficult to differentiate the grammatical and semantically acceptable structures in Pashto. Moreover, I am indebted to my teacher Dr. Muhammad Iqbal for his precious time and kind suggestions. I would also like to extend my thanks to $\mathrm{Mr}$ Akhter Hussain for his assistance in reviewing this article. At the end, I, appreciate Muhammad Farooq for his help in fee deposit process

\section{References}

Ahmed, T. (2006). Spatial, temporal and structural usages of Urdu ko. Paper presented at the Proceedings of the LFG'06 Conference.

Butt, M., Grimm, S., \& Ahmed, T. (2006). Dative subjects. Paper presented at NWO/DFG Workshop on Optimal Sentence Processing. Retrieved from http://ling.uni-konstanz.de/pages/home/butt/nijmegen-hnd.pdf

Grimm, S. (2005). The lattice of case and agentivity. Unpublished master's thesis, Universiteit van Amsterdam.

Khan, T. A. (2009). Spatial expressions and case in South Asian languages. PhD, Konstanz, Germany

Khattak, K. K. (1988). A case grammar study of the Pashto verb. School of Oriental and African Studies, University of London.

Landau, I. (2005). The locative syntax of experiencers, ms. Ben Gurion University.

Mohanan, T. (1994). Argument structure in Hindi: Center for the Study of Language (CSLI).

Rahman, G., \& Bukhari, N. H. (2014). Case System in Pashto. Kashmir Journal of Language Research, 17(1), 173-193.

Rizvi, S. M. J., Butt, M., \& King, T. H. (2008). Indications of Urdu tetravalent verbs having 'oblique agents' in the argument structure (p. 434). Proceedings of LFG08.

Roberts, T. (2000). Clitics and agreement. Massachusetts Institute of Technology. 
Saksena, A. (1980). The affected agent. Language, 56(4), 812-826. https://doi.org/10.2307/413490

Tegey, H., \& Robson, B. (1996). A Reference Grammar of Pashto.

Verma, M. K., \& Mohanan, K. P. (1990). Experiencer subjects in South Asian languages: Center for the Study of Language (CSLI).

\section{Notes}

Note 1. Dative case is focus of this study.-

Note 2. La and ta as dative case markers can be replaced for each other. This study is based on Yousufzai dialect of Pashto so preference is given to 'ta' only.

\section{Appendix A}

Different types of abbreviations that are used in this research.

$\begin{array}{ll}\text { NOM } & \text { Normative case } \\ \text { SUBJ } & \text { Subject } \\ \text { OBJ } & \text { Object } \\ \text { SG } & \text { Singular } \\ \text { PL } & \text { Plural } \\ \text { DAT } & \text { Dative case } \\ \text { ALL } & \text { Allative case } \\ \text { ERG } & \text { Ergative case } \\ \text { PRS } & \text { Present tense } \\ \text { PRS.PRF } & \text { Present Perfect } \\ \text { PST. } & \text { Past tense } \\ \text { PST.PRF } & \text { Past Perfect }\end{array}$

\section{Copyrights}

Copyright for this article is retained by the author, with first publication rights granted to the journal.

This is an open-access article distributed under the terms and conditions of the Creative Commons Attribution license (http://creativecommons.org/licenses/by/4.0/). 